\title{
Agenda em políticas públicas: a estratégia de educação financeira no Brasil à luz do modelo de múltiplos fluxos
}

CRistina TAuaf Ribeiro ${ }^{1}$

${ }^{1}$ Fundação Getulio Vargas (FGV EAESP) / Escola de Administração de Empresas de SÃo Paulo, SÃo Paulo - SP, BRASIL

\begin{abstract}
Resumo
Este artigo analisa a trajetória que levou ao estabelecimento da Estratégia Nacional de Educação Financeira (ENEF) no Brasil. Trata-se de estudo de caso sobre agenda e formulação no campo das políticas públicas e, ao se apoiar no modelo de múltiplos fluxos (MMF) de John Kingdon, identifica elementos teóricos em uma situação de caráter empírico, objetivando contribuir para o entendimento dos processos decisórios no âmbito estatal. Desde o início dos anos 2000, a inclusão financeira passou a ser vista por organismos internacionais e governos como uma frente de combate à pobreza, culminando com o lançamento, em 2010, dos Princípios para Inclusão Financeira Inovadora do Grupo dos 20 (G20). No entanto, a percepção de que a educação financeira da população é importante para a inclusão social começou a ser disseminada anos antes, pela Organização para Cooperação e Desenvolvimento Econômico (OCDE). A partir de 2003, esse órgão desenvolveu ativamente conteúdos e recomendações para a adoção de estratégias de educação financeira pelos países. No Brasil, o tema começou a ganhar corpo na agenda governamental em 2007 e tornou-se uma política pública de caráter permanente em dezembro de 2010. Calcado em pesquisa bibliográfica e documental, este estudo demonstra que a influência exercida pela OCDE não foi suficiente para despertar a atenção imediata do governo e aponta um conjunto mais complexo de fatores e atores que, orquestrados, propiciaram a convergência de fluxos que resultou na ascensão do tema à agenda de decisões.
\end{abstract}

Palavras-chave: Educação financeira. Agenda. Fluxos.

\section{Agenda-setting in public policies: the strategy for financial education in Brazil through the lens of the multiple streams model}

\section{Abstract}

This article analyzes how the National Financial Education Strategy was established in Brazil. This case study on the agenda-setting and policy formulation in the field of public policies is based on John Kingdon's multiple streams model. It aims to contribute to the understanding of government decision-making processes by identifying theoretical elements in an empirical situation. Since the early 2000 s, financial inclusion is considered by international organizations and governments as a way of fighting poverty. This culminated in the G20's Principles for Innovative Financial Inclusion, launched in 2010. However, the perception that the population's financial education is important for social inclusion was disseminated years earlier by the Organization for Economic Co-operation and Development (OECD). Since 2003, this organization has actively developed content and recommendations for the adoption of financial education strategies by countries. In Brazil, the topic gained space in the government agenda in 2007 and was a permanent public policy by December 2010. Based on bibliographical and documentary research methods, this study demonstrates that the influence exerted by the OECD was not sufficient to raise immediate government attention to the topic and points to a more complex set of factors and actors that allow the coupling of the three streams, resulting in the escalation of the topic to the decision agenda.

Keywords: Financial education. Agenda. Streams.

Agenda en políticas públicas: la estrategia de educación financiera en Brasil a la luz del modelo de corrientes múltiples

\begin{abstract}
Resumen
Este artículo analiza la trayectoria que condujo al establecimiento de la Estrategia Nacional de Educación Financiera en Brasil. Es un estudio de caso sobre agenda y formulación en políticas públicas y, al apoyarse en el modelo de corrientes múltiples de John Kingdon, identifica elementos teóricos en una situación empírica, con el objetivo de contribuir a la comprensión de los procesos decisorios públicos. Desde principios de los años 2000, los organismos internacionales y gobiernos consideran la inclusión financiera como un modo de combate a la pobreza, destacándose el lanzamiento de los Principios para la Inclusión Financiera Innovadora del G20, en 2010. Sin embargo, la percepción de que la educación financiera de la población es importante para la inclusión social comenzó a ser diseminada años antes por la Organización para la Cooperación y el Desarrollo Económico (OCDE). A partir de 2003, ese organismo desarrolló activamente contenidos y recomendaciones para la adopción de estrategias de educación financiera por parte de los países. En Brasil, el tema comenzó a crecer en la agenda gubernamental en 2007, tornándose una política pública de carácter permanente en diciembre de 2010. Basado en investigación bibliográfica y documental, este estudio demuestra que la influencia ejercida por la OCDE no fue suficiente para atraer la atención inmediata del gobierno y señala un conjunto más complejo de factores y actores que, organizados, propiciaron la convergencia de corrientes que resultó en el ascenso del tema a la agenda de decisiones del gobierno.
\end{abstract}

Palabras clave: Educación financiera. Agenda. Corrientes. 


\section{INTRODUÇÃO}

A inclusão financeira ganhou destaque a partir dos anos 2000, quando organismos internacionais e governos passaram a levantar essa bandeira como uma importante frente de combate à pobreza. Embora a tendência tenha ganhado maior relevo em 2010, com o lançamento dos Princípios para Inclusão Financeira Inovadora do Grupo dos 20 (G20), desde 2003, a Organização para Cooperação e Desenvolvimento Econômico (OCDE) já advogava sua percepção de que a educação financeira da população seria condição inescapável para um processo de inclusão bem-sucedido. Esse órgão desenvolveu e disseminou ativamente conteúdos e recomendações para a adoção de estratégias nacionais de educação financeira. No Brasil, o tema começou a tomar corpo na agenda governamental em 2007, até se tornar uma política pública de caráter permanente ${ }_{1}$, em dezembro de 2010. Por se tratar de um tema não convencional no rol de preocupações governamentais, coloca-se a pergunta: quais foram as condições e os fatores impulsionadores para que sua trajetória ganhasse força até alcançar o estabelecimento de uma política específica, a Estratégia Nacional de Educação Financeira (ENEF)?

Em políticas públicas, podemos definir agenda como uma relação de temas considerados prioritários pelo governo de um país e aos quais este se dedica. O processo de formação da agenda é fundamental, posto que encerra uma intensa disputa entre diferentes atores que buscam incluir questões de seu interesse nessa lista de prioridades, visando que tais questões se transformem em objeto de ação governamental e se concretizem como políticas públicas. $O$ estudo do processo de formação da agenda procura responder de que modo uma questão específica se torna relevante em determinado momento, a ponto de chamar a atenção do governo e passar a integrar sua agenda, além de identificar o motivo por que somente alguns casos resultam no estabelecimento de ações governamentais. Nesse sentido, Capella (2007, p. 121) argumenta que "o modo como os problemas são conceituados no processo de formulação de políticas e as maneiras pelas quais as alternativas são apresentadas e selecionadas são questões fundamentais para a compreensão da dinâmica da ação estatal".

Unindo conceitos teóricos e uma situação empírica, este artigo é um estudo de caso que objetiva contribuir para o entendimento dos processos pré-decisórios no âmbito do Estado. Em termos metodológicos, trata-se de uma análise qualitativa apoiada em pesquisa bibliográfica sobre teorias de formação de agenda e formulação em políticas públicas, bem como em pesquisa documental, valendo-se essencialmente de materiais da OCDE e da ENEF para a construção contextual sobre a qual se aplica o modelo teórico-metodológico de Kingdon (1995).

Além desta introdução, o texto se organiza em quatro seções. Primeiramente realiza-se uma breve revisão de literatura sobre a teoria de formação da agenda, com foco no modelo de múltiplos fluxos (MMF). A segunda seção apresenta o contexto, os estudos preparatórios de formulação da ENEF e as linhas gerais do plano diretor. Na terceira seção se desenvolve a análise, com o propósito de identificar os elementos da teoria de Kingdon (1995) nos processos pré-decisórios da ENEF. As considerações finais sumarizam os achados da pesquisa e trazem sugestões para o desenvolvimento de futuros estudos.

\section{Formação da agenda em políticas públicas - uma breve revisão de literatura}

Na literatura sobre políticas públicas, dois modelos teóricos se destacam com o intento de explicar como as agendas governamentais são formadas e como as alternativas se apresentam aos formuladores de políticas: o MMF, de Kingdon (1995) e o modelo de equilíbrio interrompido (MEI), de Baumgartner e Jones (1993). Segundo Capella (2007, p. 120), esses dois modelos procuram mostrar que o processo de formulação de políticas está mais próximo do campo das ideias, da argumentação e da discussão do que de técnicas formais de solução de problemas.

Os dois modelos guardam muitas semelhanças, porém, uma das principais diferenças entre ambos é a relevância do papel atribuído à mídia e aos grupos de interesse, como destacado por Capella (2007, p. 116-120). Enquanto o MEl considera que a mídia direciona a atenção dos indivíduos, sendo fundamental no processo de formação da agenda, no MMF a mídia apenas retrata questões já presentes na agenda, não influenciando sua formação. Em relação aos grupos de interesse, o MEl enfatiza que tais grupos assumem papel crucial na definição das questões da agenda, ao passo que o MMF aponta a atuação desses atores mais no sentido de bloquear questões do que de levá-las à agenda. No estudo de caso apresentado a seguir, optou-se pela aplicação do MMF, uma vez que não foram encontradas evidências empíricas suficientes sobre o tratamento do tema pela

${ }_{1}^{1}$ Para os efeitos deste artigo, considera-se o sentido de perenidade da política pública de caráter permanente, ou seja, ela não apresenta um cenário de descontinuidade. 
mídia antes que culminasse em ação governamental, tampouco acerca da proeminência de grupos de interesse específicos agindo no sentido de influenciar a opinião pública para forçar a inserção da questão na agenda governamental ou sua posterior ascensão à agenda de decisões. O modelo também se mostrou pertinente para a análise do caso escolhido porque: a) seus elementos conceituais facilitam a identificação do papel exercido por diferentes categorias de atores e contextos na dinâmica pré-decisória; b) caracteriza-se pela escolha top-down de temas da agenda; e c) trata da intersetorialidade na especificação de alternativas.

Originalmente aplicado por Kingdon (1995) à análise da formação de agenda em políticas federais de saúde e transporte dos Estados Unidos da América (EUA), o MMF foi testado empiricamente por inúmeros autores em políticas nacionais, internacionais e locais e em países e setores diversos. Uma meta-análise realizada por Jones, Peterson, Pierce et al. (2016) reportou que, no período de 2000 a 2013, foram publicados, somente em língua inglesa, 311 artigos que aplicaram os conceitos do MMF. Nas últimas duas décadas, a matriz de Kingdon (1995) também serviu de lente teórica para um aprofundamento dos estudos sobre formação de agenda em políticas públicas no Brasil. Nesse campo, Capella (2008), Pereira e Teixeira (2011) e Nagem e Silva (2013) demonstraram que diferentes políticas públicas de âmbito nacional emergiram de uma confluência de processos sociais, políticos e econômicos que guardam características comuns, embora os atores, conteúdos, momentos e contextos sejam totalmente diversos. Com o intuito de embasar a análise apresentada adiante, o restante desta seção se dedica a uma abordagem conceitual do MMF.

O modelo de Kingdon (1995) se desenvolve a partir de uma combinação do modelo racional de policy cycle com o modelo garbage $\mathrm{can}_{2}$. Para o autor,

[...] de uma maneira bastante simplificada, podemos considerar que a formulação de políticas públicas é um conjunto de processos, incluindo pelo menos: 1) o estabelecimento de uma agenda; 2) a especificação das alternativas a partir das quais as escolhas são feitas; 3 ) uma escolha final entre estas alternativas específicas, por meio de votação no Legislativo ou decisão presidencial; e 4) a implementação desta decisão (KINGDON, 2006a, p. 221).

A teoria tem como foco as etapas 1 e 2, definidas como "processos pré-decisórios" (KINGDON, 2006b, p. 225). Nesses processos, as influências que levam à escolha final são determinadas por duas categorias de fatores: os participantes ativos (governamentais e não governamentais) e os processos pelos quais os itens da agenda e as alternativas ganham proeminência (PINTO, 2008, p. 15).

Kingdon faz uma classificação da agenda em três níveis. A agenda sistêmica é a lista de assuntos preocupantes ao país, mas para os quais o governo ainda não dispensa atenção específica (VIANA, 1996), enquanto as agendas governamentais são "as listas de temas que são alvo de séria atenção por parte de funcionários do governo" e a agenda de decisões é "a lista de temas que é alvo de deliberação" (KINGDON, 2006b, p. 234).

Para explicar como algumas questões passam a ser efetivamente consideradas pelos formuladores de políticas públicas e como uma questão migra da agenda governamental para a agenda de decisões, Kingdon (1995) caracteriza o governo como uma anarquia organizada, na qual 3 fluxos decisórios seguem seu curso de modo independente. Esses 3 fluxos são: problemas, soluções ou políticas públicas (alternativas) e política.

O fluxo dos problemas está relacionado com os meios pelos quais os atores governamentais tomam conhecimento das situações e também com as formas pelas quais essas situações são definidas como problemas: "as situações passam a ser definidas como problemas e aumentam suas chances de se tornarem prioridade na agenda, quando acreditamos que devemos fazer algo para mudá-las" (KINGDON, 2006b, p. 227). Sobre os meios, o autor destaca: a) indicadores (medidas que revelam a magnitude de uma situação e as mudanças pelas quais ela passa); b) eventos-foco (crises, símbolos e outras ocorrências que chamem atenção para algumas situações mais do que outras); e c) feedback de ações governamentais (podem ser formais, como monitoramento de custos ou avaliação de programas, ou informais, como manifestações na imprensa). Partindo do princípio de que problemas são construções sociais, as formas de definição de uma situação como problema dependem da interpretação dos meios e podem revelar situações de ameaça a valores importantes, disparidades indesejáveis na comparação

${ }^{2}$ Sobre o modelo garbage can, ou "lata de lixo", de March, Olsen e Cohen (1972), Souza (2006, p. 31) sintetiza: "o modelo advoga que soluções procuram por problemas. As escolhas compõem um garbage can no qual vários tipos de problemas e soluções são colocados pelos participantes à medida que eles aparecem". 
com outros países/regiões, ou a classificação em categorias que chamem mais atenção do que outras. A classificação de uma situação como problema é estrategicamente importante para o sucesso da alocação de uma questão na agenda.

O fluxo das soluções ou das políticas públicas, por sua vez, refere-se a um conjunto de alternativas para solucionar problemas. Para Kingdon, as ideias geradas nesse fluxo não estão necessariamente relacionadas à percepção de problemas específicos e, consequentemente, as questões presentes na agenda governamental não representam necessariamente o casamento entre problemas e soluções. Como observado por Capella (2007), o autor assegura às ideias um papel crucial em seu modelo, argumentando que elas são frequentemente mais importantes na escolha de uma alternativa do que a influência de grupos de pressão.

Inspirado no processo biológico de seleção natural, Kingdon (1995) batizou de policy primeval soup (caldo primitivo de políticas) o processo em que inúmeras ideias são formuladas e confrontadas entre si pelas policy communities (grupos de especialistas governamentais e não governamentais), sendo que só algumas sobrevivem e satisfazem os critérios geralmente estabelecidos de factibilidade técnica, aceitação e força de consenso (VIANA, 1996, p. 9). A esse respeito, Kingdon (2006b, p. 232) argumenta que "a avaliação de propostas, em parte, leva em consideração o apoio político ou a oposição, mas é também, por outro lado, baseada em critérios lógicos e analíticos" e que as alternativas escolhidas precisam ser difundidas com persuasão em diferentes fóruns, "num longo processo de amaciamento" no qual a reelaboração é mais importante do que a transformação.

O autor atesta que o fluxo da política flui de acordo com dinâmica e regras próprias, sendo o consenso alcançado por meio da negociação mais do que da persuasão (KINGDON, 2006b). Três elementos exercem influência sobre tal fluxo: a) o national mood (ou clima nacional) é expresso por movimentos sociais, mídia e outros - percepção, pelos participantes do processo decisório, de que a sociedade é favorável a determinadas questões; b) as forças organizadas - grupos de interesses que apoiam ou tentam obstruir o acesso de uma questão à agenda e que poderão impor custos políticos para determinadas escolhas; e c) o turnover (mudanças de governo) que podem resultar do processo eleitoral ou podem ser internas ao governo, envolvendo pessoas em posição estratégica, como ministros e funcionários de alto escalão, alterações na composição do Congresso Nacional e, ainda, mudanças de competência sobre determinadas questões. Segundo Kingdon, no fluxo da política, os fatores que mais influenciam a formação e a alteração da agenda governamental são national mood e turnover (CAPELLA, 2007).

Os três fluxos são independentes, mas as mudanças na agenda dependem da convergência entre eles, catalisada por uma atuação empreendedora. Às circunstâncias que possibilitam essa convergência, Kingdon denomina janelas de oportunidade. Segundo o autor, "um elo completo combina as três dinâmicas - problemas, políticas públicas e política - num único pacote" (KINGDON, 2006b, p. 234), ou seja, é o momento em que um problema é reconhecido, uma solução está disponível e as condições políticas são propícias, possibilitando que questões ascendam à agenda de decisões (CAPELLA, 2016). As janelas se abrem nos fluxos do problema ou da política e fornecem o contexto institucional, as restrições e as oportunidades dentro das quais políticas públicas são criadas (JONES, PETERSON, PIERCE et al., 2006).

No processo em torno dos fluxos, Kingdon (1995) propõe uma tipologia de atores, de acordo com suas diferentes contribuições. Começando pelos empreendedores de política, que são peças-chave na identificação de janelas de oportunidade e na convergência entre os fluxos, Capella (2007, p. 97) observa que "desempenham um papel fundamental, unindo soluções a problemas; propostas a momentos políticos; eventos políticos a problemas". Para o autor, os empreendedores são indivíduos ou pequenos grupos de pessoas que se engajam na defesa de uma ideia e são capazes de perceber os momentos oportunos para conectá-las a problemas e soluções. Esses empreendedores investem seus recursos (tempo, energia, reputação, recursos financeiros) visando a obter benefícios que podem ser ganhos materiais, promoção de valores e ideologias ou o simples prazer de participar do jogo. Seu sucesso depende de três fatores críticos, sintetizados por Jones, Peterson, Pierce et al. (2016): recursos, acesso aos decisores e senso estratégico.

Ainda no campo dos atores, ao distinguir participantes visíveis como sendo aqueles que recebem maior atenção do público (presidente, assessores de alto escalão, membros do Congresso Nacional, mídia e partidos políticos) e participantes invisíveis como os especialistas que compõem as policy communities (burocratas de carreira, acadêmicos, pesquisadores e analistas que trabalham para grupos de interesse), Kingdon (2006b, p. 230, grifo nosso) faz a seguinte digressão: "o grupo de atores visíveis define a agenda enquanto o grupo de atores invisíveis tem maior poder de influência na escolha de alternativas". Essa constatação denota o caráter top-down na escolha dos temas e a importância da intersetorialidade na especificação de alternativas. Em suas pesquisas, Kingdon reconheceu no chefe máximo do Poder Executivo o ator visível mais influente na 
formação da agenda, enquanto a mídia seria o menos relevante (por acreditar que esta se interessa em transmitir as questões ao público somente depois que a agenda está formada), e os grupos de interesse teriam atuação obstrutora, porém, nunca forte o suficiente para alçar uma questão à agenda exclusivamente por sua ação (CAPELLA, 2007).

O MMF emergiu como um grande avanço teórico em políticas públicas, mas nem por isso esteve isento de críticas. Dentre as principais, destacam-se as de Sabatier (2007) e Mucciaroni (1992). Para Sabatier (2007), a hipótese de independência dos fluxos não pode ser falseada, pois Kingdon não esclarece como identificar quais atores e/ou tarefas estão presentes em quais fluxos. $O$ autor também alega que a ausência de especificação das motivações causais decorre de não haver um modelo claro de ação individual. Já Mucciaroni (1992), considera o MMF extremamente descritivo e dotado de baixo poder preditivo, adequando-se apenas a estruturas institucionais fragmentadas, baseadas em participação pluralista e em coalizões temporárias, o que reduziria seu potencial explicativo a depender do sistema político vigente. Mucciaroni (1992) também coloca em dúvida a independência entre os fluxos e sugere que alterações em um provocam mudanças nos outros, tornando a convergência menos fortuita e o processo mais intencional e estratégico.

Em suma, o modelo de Kingdon, diferentemente das abordagens racionalistas de formulação de políticas, pauta-se por condições de ambiguidade, ou seja, situações em que há mais de uma forma de pensar sobre um fenômeno ou uma questão. A ambiguidade promove inovação e o MMF fornece ferramentas analíticas para explicar como e sob quais condições os sistemas e as organizações políticas dão sentido a esse cenário (ZAHARIADIS, 2007).

\section{A Estratégia Nacional de Educação Financeira - dos desdobramentos internacionais e contexto nacional ao plano diretor}

No início de 2000, a constatação da forte correlação entre pobreza e exclusão financeira lançou luz sobre o debate internacional acerca do desenvolvimento econômico, culminando com a definição dos Princípios para Inclusão Financeira Inovadora do G20. O quinto desses nove princípios estabelece que os países membros devem promover educação e capacitação financeira (GPFI, 2010).

Embora os Princípios do G20 tenham sido estabelecidos somente em 2010, a OCDE já havia se engajado no tema da educação financeira desde 2003, quando estabeleceu o "Financial Education Project" (OECD, 2004). Com base em questionários, a equipe do projeto levantou o estado da arte da educação financeira em países membros, posteriormente elaborando uma extensa publicação (OECD, 2005b), na qual apresentou tipificação e avaliação dos programas existentes. Desse projeto também resultou um documento denominado Recommendation on principles and good practices for financial education and awareness (OECD 2005a), no qual o conselho da OCDE convidou países membros e não membros a considerar as recomendações ali descritas e a disseminar os princípios e as boas práticas entre instituições dos setores público e privado, com e sem fins lucrativos, que estivessem envolvidas no tema. Esse mesmo documento serviu de base para a definição adotada pelo Brasil em seu plano diretor (ENEF, 2010a, p. 20):

Educação financeira é o processo mediante o qual os indivíduos e as sociedades melhoram sua compreensão dos conceitos e dos produtos financeiros, de maneira que, com informação, formação e orientação claras, adquiram os valores e as competências necessários para se tornarem conscientes das oportunidades e dos riscos neles envolvidos e, então, façam escolhas bem informados, saibam onde procurar ajuda, adotem outras ações que melhorem o seu bem-estar, contribuindo, assim, de modo consistente para formação de indivíduos e sociedades responsáveis, comprometidos com o futuro.

Em 2008 a OCDE criou uma rede, a International Network for Financial Education (INFE), para promover e facilitar a cooperação internacional sobre o tema, permitindo a participação de países não membros.

Para a OCDE, em um cenário no qual o acesso a serviços financeiros se mostra cada vez mais fácil, concomitantemente a um aumento dos riscos transferidos aos indivíduos devido à sofisticação e complexidade dos instrumentos disponíveis, a educação financeira se tornou um complemento valioso à inclusão financeira e proteção ao consumidor, além de também ser importante para restaurar a confiança nos mercados financeiros e contribuir para a estabilidade financeira (OECD, 2015).

Simultaneamente a essa movimentação nos fóruns internacionais, o Brasil vivenciou importantes transformações que implicaram crescente demanda de consumidores por produtos e serviços financeiros. A partir de 2002, até o agravamento da crise econômica, em 2015, a pirâmide socioeconômica brasileira passou por uma perceptível mudança em sua base. 
Programas sociais, estabilidade macroeconômica, crescimento do produto interno bruto (PIB), aumentos reais do salário mínimo e elevação do emprego formal foram os principais fatores determinantes da mobilidade de renda experimentada pela população menos favorecida e que ocasionou a proeminência da "nova classe C".

Segundo Neri e Carvalhaes (2008), a desigualdade de renda medida pelo índice de Gini sofreu redução de 0,6068 em 1993 para 0,5546 em 2007, enquanto a pobreza extrema teve um decréscimo de mais de $58 \%$ no mesmo período. Os autores afirmam, com base em dados da Pesquisa Nacional por Amostra de Domicílios do Instituto Brasileiro de Geografia e Estatística (PNAD/ IBGE), que, em 2007, a nova classe C correspondia a 47\% da população brasileira, diante de 31\% em 1993.

Assim, os temas de inclusão financeira ganharam destaque no Brasil não somente sob influência de recomendações internacionais, mas pela pressão do novo contexto socioeconômico e demográfico. Essa nova realidade, acompanhada pela crescente sofisticação do sistema financeiro, demanda que os indivíduos estejam preparados para fazer escolhas que não os prejudiquem.

Nesse cenário, em 2007, o Comitê de Regulação e Fiscalização dos Mercados Financeiro, de Capitais, de Seguros, de Previdência e Capitalização (Coremec) deliberou pela constituição de um grupo de trabalho (GT), com o objetivo de delinear uma estratégia de âmbito nacional para a educação financeira, em conjunto com representantes do governo, da iniciativa privada e da sociedade civil, de modo a construir uma proposta com legitimidade e estabelecer compromisso para sua execução.

O Coremec foi criado em 2006, para coordenar e aprimorar a atuação das agências federais que administram e controlam atividades relacionadas ao sistema financeiro e à captação pública de poupança popular. Constituído pelo presidente do Banco Central do Brasil (BCB) e por um diretor dessa autarquia, pelo presidente da Comissão de Valores Mobiliários (CVM) e por um diretor dessa autarquia, pelo Secretário de Previdência Complementar (da antiga Secretaria de Previdência Complementar [SPC], posteriormente Superintendência Nacional de Previdência Complementar [PREVIC]), do Ministério da Previdência Social, e por um diretor dessa secretaria, e, pelo Superintendente da Superintendência de Seguros Privados (SUSEP) e por um diretor dessa superintendência, suas funções eram: a) propor a adoção de medidas que objetivam o funcionamento correto dos mercados financeiro e de capitais; $b$ ) debater iniciativas regulatórias e supervisoras que possam harmonizar as atividades de seus membros; e c) facilitar e coordenar a troca de informação entre seus membros e as organizações internacionais. O GT em questão foi originalmente constituído por funcionários indicados por cada uma das agências integrantes do comitê e coordenado pela CVM.

\section{Os estudos preparatórios para a formulação da Estratégia Nacional de Educação Financeira3}

Como ponto de partida, o GT considerou três fontes de informação para dimensionar as principais necessidades de educação financeira do país: a) uma pesquisa nacional; b) experiências de outros países; e c) o levantamento das iniciativas de educação financeira existentes no país.

A pesquisa nacional foi realizada em 2008, com propósito de mensurar o grau de educação financeira da população. Foram entrevistadas 1.809 pessoas, com diferentes perfis de renda e níveis de escolaridade, em seis capitais - Porto Alegre, Salvador, Brasília, São Paulo, Recife e Rio de Janeiro. Os resultados mostraram que as pessoas não planejam seus gastos no longo prazo, demoram para se preparar financeiramente para a aposentadoria, não estão cientes dos riscos oferecidos pelos instrumentos financeiros, tampouco dos recursos para sua proteção, têm dificuldades para tomar decisões a respeito de empréstimos e investimentos e são vulneráveis a fraudes.

Ao analisar experiências internacionais, o GT apurou que em países como EUA, Reino Unido, Espanha, Austrália e Nova Zelândia a necessidade de educar financeiramente os cidadãos é largamente reconhecida, devido à percepção de fatores como a crescente complexidade e variedade de produtos financeiros, o aumento na expectativa de vida e as mudanças na composição e distribuição de renda. Nesses países há uma proliferação de iniciativas desenvolvidas por governos, entidades do setor privado e sociedade civil, voltadas a diferentes públicos (crianças, adultos, famílias, comunidades etc.), porém, notou-se que, em alguns casos, os esforços de marketing e de educação se confundem.

Já o mapeamento de iniciativas de educação financeira existentes no país identificou ações do próprio governo e realizou uma "chamada" pela internet, aplicando os critérios de gratuidade e prevalência do interesse público para excluir programas com potenciais conflitos de interesses. Foram identificadas várias iniciativas do setor financeiro e de organizações não governamentais

${ }^{3}$ Este subitem foi elaborado com base no plano diretor da ENEF e no documento "Brazil: Implementing the National Strategy", que faz parte do estudo Advancing national strategies for financial education (OECD e G20, 2013). 
(ONGs), porém, constatou-se não haver qualquer coordenação entre elas. A partir desses estudos, elencaram-se nove temas para aprofundamento: planejamento financeiro; economia; serviços financeiros; crédito e juros; investimentos; previdência social; seguros; capitalização; e, proteção e defesa do consumidor. Desse aprofundamento, ainda no âmbito do GT, derivaram os primeiros passos de formulação da ENEF, servindo de subsídio para o desenvolvimento de uma matriz de conteúdo e de um plano de ação para guiar a educação financeira de jovens e adultos.

Adicionalmente, o GT fez um mapeamento de stakeholders, identificando atores relacionados aos receptores finais da política, tais como: representantes de instituições públicas de ensino nos níveis federal, estadual e municipal; instituições públicas ligadas aos nove temas mencionados acima; e instituições privadas da jurisdição de cada um dos reguladores - mercados financeiro, de capitais, de seguros, de planos de previdência e de capitalização.

A etapa seguinte consistiu na inserção desses stakeholders como membros auxiliares do GT, dada a percepção de que seria inviável planejar e executar uma estratégia nacional de educação financeira apenas com apoio dos órgãos reguladores que compunham o Coremec. Foram convidados representantes do Ministério da Fazenda, do Ministério da Educação, do Ministério da Justiça e do Ministério da Previdência Social, do Conselho Nacional dos Secretários da Educação (CONSED), da União Nacional dos Dirigentes Municipais de Educação (UNDIME), das secretarias estaduais de educação, da Bolsa de Valores e Mercadorias (à época denominada BM\&FBovespa), da Federação Brasileira de Bancos (Febraban), da Associação Brasileira das Entidades do Mercado Financeiro e de Capitais (Anbima) e da Confederação Nacional das Empresas de Seguros Gerais, Previdência Privada e Vida, Saúde Suplementar e Capitalização (CNSeg). A consulta também se estendeu a especialistas em pedagogia, psicologia econômica, didática e comunicação, para que contribuíssem na definição de diretrizes para o Ensino Infantil, o Ensino Fundamental e o Ensino Médio.

\section{O plano diretor da Estratégia Nacional de Educação Financeira}

O resultado do trabalho desenvolvido pelo GT em conjunto com os stakeholders foi o delineamento da ENEF sob a forma de um plano diretor contendo descrições de cenários, desafios e um guia com diretrizes para a formulação de conteúdos e ações, além de uma proposta de governança.

A criação oficial da ENEF se baseou nesse plano diretor, cujos objetivos são: a) promover a educação financeira e previdenciária; b) aumentar a capacidade do cidadão para realizar escolhas conscientes sobre a administração dos seus recursos; e c) contribuir para a eficiência e a solidez dos mercados financeiro, de capitais, de seguros, de previdência e de capitalização. Assim:

A Estratégia Nacional de Educação Financeira - ENEF - é uma mobilização multisetorial em torno da promoção de ações de educação financeira no Brasil. A estratégia foi instituída como política de Estado de caráter permanente, e suas características principais são a garantia de gratuidade das iniciativas que desenvolve ou apoia e sua imparcialidade comercial. O objetivo da ENEF, criada através do Decreto Federal 7.397/2010, é contribuir para o fortalecimento da cidadania ao fornecer e apoiar ações que ajudem a população a tomar decisões financeiras mais autônomas e conscientes (ENEF, 2017).

As ações da ENEF são compostas por programas transversais e setoriais, coordenados de modo centralizado, mas executadas de modo descentralizado. As iniciativas transversais contemplam programas de caráter multidisciplinar, com alcance nacional e que necessitam da articulação de diversos setores governamentais, instituições privadas e sociedade civil para sua formulação e implementação. Dividem-se em dois grupos: educação financeira nas escolas, para crianças e jovens; e educação financeira para adultos. Adicionalmente, as iniciativas setoriais se referem a ações de entidades públicas ou privadas, com objetivos e públicos-alvo específicos, desenvolvidas de maneira independente, mas integradas à ENEF a partir do reconhecimento de sua aderência aos objetivos do plano diretor.

A fim conferir viabilidade econômico-financeira e de implementação ao projeto, o plano diretor previu a manutenção da articulação entre as diversas instâncias de governo e a iniciativa privada, com a coordenação centralizada na figura do Comitê Nacional de Educação Financeira (CONEF) $)_{4}$ e a execução descentralizada em uma estrutura de governança que institucionalizou as parcerias com o setor privado, iniciadas no contexto do GT.

${ }^{4} \mathrm{O}$ CONEF foi concebido como instância responsável pela direção, supervisão e fomento da ENEF, sendo integrado por sete órgãos e entidades de governo e seis organizações da sociedade civil. 


\section{O modelo de múltiplos fluxos aplicado à Estratégia Nacional de Educação Financeira}

Partindo do referencial teórico do MMF, da contextualização e da descrição das etapas pré-decisórias da ENEF abordadas nas seções anteriores, pode-se identificar a trajetória do tema educação financeira entre os diferentes níveis da agenda e, ainda, explorar os processos de reconhecimento do problema (fluxo do problema), especificação de alternativas (fluxo da política pública) e ambiente político (fluxo da política), que culminaram com a janela de oportunidade para sua inserção na agenda de decisões. Inicialmente, pode-se inferir que a presença do tema na agenda sistêmica se deu, em grande medida, pelas sucessivas ações da OCDE, chamando a atenção de países membros e não membros para a importância da educação financeira nos contextos de desenvolvimento e bem-estar, defesa do consumidor e estabilidade do sistema financeiro. A OCDE é instituição influente em fóruns internacionais e da qual o Brasil vinha se aproximando desde o ano 2000, por meio de participação ou observação em diversos comitês. De acordo com informações disponíveis no site do Ministério da Fazenda (2019), em maio de 2007, o Conselho Ministerial da OCDE decidiu fortalecer a cooperação com o Brasil, a China, a Índia, a Indonésia e a África do Sul em um programa de enhanced engagement, com vistas a uma possível adesão desses países ao organismo.

Outros três fatores indicam a presença da educação financeira na agenda sistêmica brasileira: a) a crescente complexidade do sistema financeiro e a vulnerabilidade dos indivíduos a crises, que podem ser consideradas eventos-foco; b) a ampliação da inclusão financeira da população menos favorecida em decorrência das transformações sociais vivenciadas pelo país, que seriam indicadores; e c) a adoção de soluções parciais com iniciativas não coordenadas de educação financeira por parte de atores do setor privado e algumas agências governamentais, caracterizando o feedback.

\section{Fluxo do problema}

A passagem do tema para a agenda governamental se dá no momento em que o Coremec institui o GT e designa funcionários dos respectivos órgãos que o compõem para fazer um levantamento do nível de educação financeira da população brasileira, estudar as experiências internacionais e as iniciativas nacionais e propor uma estratégia de âmbito nacional. Os membros do GT assumem, assim, o papel de atores invisíveis.

Embora não haja evidência documental que comprove de onde partiu a demanda que influenciou essa deliberação do Coremec, a observação do contexto possibilita interpretar que foi um caminho natural, tendo em vista os esforços de inclusão financeira que já vinham sendo empenhados há alguns anos, como a regulamentação dos correspondentes bancários pelo $\mathrm{BCB}$ e os programas de incentivo ao microcrédito. É provável que atores visíveis próximos à presidência e responsáveis pelas diretrizes de governo na área econômica, cientes desses esforços e em uma leitura dos indicadores resultantes das políticas socioeconômicas, tenham entendido a educação financeira como necessidade complementar para o sucesso do projeto mais abrangente de inclusão financeira e empoderamento da nova classe C. Como fator adicional, também não se deve rejeitar a hipótese de que esses mesmos atores tenham vislumbrado na ENEF uma oportunidade de aumentar a visibilidade do Brasil perante a $\mathrm{OCDE}$, aspirando a alcançar o posto de país membro. O GT constrói, então, uma visão mais holística da situação, passando a defini-la como problema. Em uma aplicação dos conceitos de Kingdon (2006b), esse processo se dá por comparação com outros países que já haviam iniciado suas estratégias nacionais de educação financeira e, ainda, pela constatação de ameaça a valores importantes, pois a pesquisa revelou que, apesar do aumento da renda, a população continuou com perfil mais propenso a gastar do que a poupar, resultando em altos índices de endividamento, inadimplência e despreparo para a aposentadoria. A caracterização do problema se tornou ainda mais evidente a partir de um novo evento-foco: a crise financeira global de 2008 e seus reflexos.

\section{Fluxo das políticas públicas}

Em paralelo aos estudos, o GT também avançou na especificação de alternativas. Com o envolvimento de outros setores do governo, especialistas em questões educacionais e atores do setor privado, que, sob a ótica de Kingdon podem ser identificados como policy communities, deu-se o processo de policy primeval soup que marca o fluxo das políticas públicas. A proposição de uma estrutura de governança em rede com coordenação centralizada, respeitando a transversalidade do tema e a intersetorialidade da execução, foram fatores-chave para o atendimento a padrões de viabilidade técnica e flexibilidade orçamentária do projeto, aumentando suas chances de escolha. Essas características indicam forte aderência aos critérios lógico-analíticos, de factibilidade técnica, aceitação e força de consenso destacados por Viana (1996) e Kingdon (2006b). 


\section{Fluxo da política}

Dentre os três elementos apontados por Kingdon (2006b) como influentes no fluxo da política, é o national mood que se observa com maior clareza no caso da ENEF. Os oito anos do governo Lula foram marcados por uma agenda de forte caráter social. Ao final do segundo mandato, a eleição de uma sucessora oriunda do mesmo partido, e com seu apoio, evidencia um humor nacional favorável, com a população expressando nas urnas sua aprovação às políticas que vinham sendo adotadas. O clima político predominante em dezembro de 2010, quando da assinatura do decreto presidencial que instituiu a ENEF, mostrava-se altamente propício a medidas voltadas ao empoderamento das camadas menos privilegiadas da população.

Por outro lado, descarta-se que a ascensão da ENEF à agenda de decisões tenha sido decorrente do que Kingdon (2006b) conceitua como turnover, haja vista que a assinatura do decreto tenha ocorrido ao final do mandato presidencial. Restaria, então, a possibilidade de ter sido motivada pela iminência do turnover, que colocaria em risco a continuidade do projeto devido à mudança de governo. No entanto, essa hipótese também se mostra improvável, uma vez que a presidente eleita se comprometeu a seguir uma linha semelhante à de seu antecessor, inclusive com a manutenção de quadros, como foi o caso dos ministros Guido Mantega e Fernando Haddad (Fazenda e Educação, respectivamente), cujas equipes estavam envolvidas nesse projeto.

No que tange à atuação de forças organizadas, Martins (2013) aponta que, dentre os membros auxiliares convidados a constituir o GT, a predominância de representantes empresariais do sistema financeiro, diante da ausência de representantes da sociedade civil e de defensores dos direitos do consumidor, deu margem a um desequilíbrio de interesses. Prestadores de serviços financeiros monopolizaram um canal de interlocução que deveria ter sido dividido com a população consumidora de tais serviços, que é justamente o público-alvo da ENEF. A inclusão de representantes de instituições como o Instituto Brasileiro de Defesa do Consumidor (IDEC) teria reduzido tal assimetria. Em que pese à influência do setor privado no teor do plano diretor, sua persuasão para a abertura da janela política é menos evidente do que aquela exercida pelo national mood.

\section{A janela de oportunidade e a convergência dos fluxos}

Com o avanço dos trabalhos do GT, o reconhecimento do problema se tornou cada vez mais claro e, em paralelo, as alternativas de solução desenhadas pelos atores invisíveis e pelas policy communities foram amarradas sob a forma de plano diretor. Em 2009, quando a proposta foi apresentada ao Coremec, o órgão deliberou a criação de um novo GT, dessa vez sob coordenação da SUSEP, com o propósito de coordenar os atos necessários à instituição da ENEF, dentre os quais realizar uma audiência restrita para reunir sugestões de alterações à proposta, avaliar possibilidades de parceria para execução dos programas e redigir o ato normativo (COREMEC, 2009). Ao final de 2010, quando os trabalhos do GT foram concluídos e a proposta de política pública estava pronta, os traumas da crise financeira internacional de 2008 ainda reverberavam como alerta e o $\mathrm{G} 20$ havia recém-anunciado, em reunião de maio de 2010, os Princípios para Inclusão Financeira Inovadora (GPFI, 2010), caracterizando uma janela do problema. Na mesma ocasião, o cenário político se mostrava propício, com um final de mandato pautado pelo national mood favorável a políticas de inclusão, além da promessa de continuidade pelo novo governo que se iniciaria, configurando uma janela da política. Segundo Martins (2013, p. 72), a proposta da ENEF:

[...] surge num contexto caracterizado, de um lado, por uma associação de indicadores positivos na economia doméstica como o histórico crescimento da carteira de crédito; a vigorosa atividade econômica no período de 2005 a 2008; a robustez do mercado de trabalho e o crescimento sem precedentes da nova classe média e, de outro, por uma forte crise financeira internacional, pelos crescentes índices de inadimplência e de endividamento das famílias. É possível identificar esse contexto à luz da janela de oportunidade de Kingdon.

Para Kingdon (2006b, p. 236), "uma janela aberta para políticas públicas constitui uma oportunidade para que os defensores de uma determinada causa ofereçam suas soluções, ou para chamar atenção para problemas que considerem especiais", papel que, no caso apresentado, foi desempenhado pelo Coremec. O comitê se mostrou dotado dos fatores elencados por Jones, Peterson, Pierce et al. (2016) como essenciais para o sucesso de empreendedores de política: recursos disponíveis; acesso aos decisores; e senso estratégico. Esse pequeno grupo de pessoas, formado pelos dirigentes máximos das agências reguladoras do sistema financeiro, tinha à sua disposição funcionários altamente qualificados para a realização dos estudos e o desenho das alternativas, tinha acesso direto a pelo menos um ator visível ligado à presidência - o ministro da Fazenda - e, após três anos de trabalho, fez a correta identificação da janela de oportunidade. 
Outro fator que confirma o papel do Coremec como empreendedor é a promoção da intersetorialidade nas etapas pré-decisórias, ao permitir a participação de membros auxiliares externos no GT. A atuação de representantes de diversos ministérios e de entidades do setor privado contribuiu para neutralizar quaisquer grupos de interesse que pudessem atuar como forças contrárias à ascensão da ENEF, pois, ao participarem da formulação e escolha das alternativas, não teriam argumentos para se opor ao resultado final. O Coremec se mostrou dotado das três características fundamentais para o sucesso de empreendedores de política, segundo Jones, Peterson, Pierce et al. (2016): recursos; acesso aos decisores; e senso estratégico.

A convergência dos fluxos alçou a ENEF à agenda de decisões do governo. O marco de encerramento das etapas pré-decisórias se dá com a promulgação do Decreto n. 7.397, em 22 de dezembro de 2010 (BRASIL, 2010), oficializando a estrutura de governança que visa à contínua formulação, implementação e avaliação da nova política pública de caráter permanente e nacional.

\section{CONSIDERAÇÕES FINAIS}

Situando-se no campo de estudos sobre formação de agenda em políticas públicas, este artigo partiu do arcabouço teórico de Kingdon (1995, 2006a, 2006b) para embasar um estudo de caso sobre os caminhos que levaram ao lançamento da ENEF.

A OCDE e outros fóruns internacionais apontam a educação financeira como condição fundamental para o bem-estar da população e para o desenvolvimento socioeconômico, recomendando a adoção de estratégias nacionais com o intuito de preparar os indivíduos para tomarem decisões conscientes em relação às suas finanças. Esse reconhecimento, no entanto, não se mostra evidente e "automático" em um país com tantas prioridades sociais e econômicas como o Brasil. Portanto, buscou-se identificar o processo que levou ao convencimento de que uma estratégia de educação financeira deveria fazer parte da agenda governamental e de que maneira as soluções foram costuradas levando à adoção de uma política pública nesse âmbito.

No caso analisado, constata-se que a influência exercida pela OCDE desde 2003 não foi suficiente para que a educação financeira despertasse atenção imediata por parte do governo. As condições para tal foram construídas ao longo do tempo, pela percepção da conjuntura nacional, pelo amadurecimento natural dos esforços com vistas a um objetivo maior (a inclusão financeira) e, mais tarde, pelos efeitos de eventos inesperados (crise financeira global de 2008) e pela comparação com a realidade de outros países. Sem a definição de uma situação como problema, a educação financeira não teria se destacado como prioridade na agenda. A viabilidade do projeto e sua eficaz comunicação por meio de um plano diretor apresentado em um contexto político favorável culminaram no estabelecimento da política pública.

O exercício de transposição dos elementos teóricos propostos por Kingdon (1995, 2006a, 2006b) ao caso estudado lançou luz sobre a importância da convergência entre identificação de problemas, soluções disponíveis e contexto político para que o projeto lograsse aprovação. Ao demonstrar empiricamente que a existência de soluções pré-fabricadas não possibilita, por si só, a entrada e escalada de um tema na agenda governamental, o artigo contribui não somente para o entendimento desse caso específico, mas para a compreensão do processo decisório na esfera estatal como um todo, o que poderá ser útil para aprimorar a condução de etapas pré-decisórias em novos projetos. Outro ponto de destaque do artigo se refere ao caráter sui generis da política aqui exposta, tanto pela não convencionalidade do tema, como pela estrutura atípica de compartilhamento de responsabilidades com o setor privado. Por esse motivo, sugere-se que futuros estudos sobre a ENEF se debrucem sobre os desafios enfrentados na formulação e implementação em razão de sua complexa estrutura de governança em rede.

\section{AGRADECIMENTOS}

O presente trabalho foi realizado com apoio da Coordenação de Aperfeiçoamento de Pessoal de Nível Superior - Brasil (CAPES) - código de financiamento 001. 


\section{REFERÊNCIAS}

BAUMGARTNER, F.; JONES, B. Agendas and instability in American politics. Chicago: University of Chicago Press, 1993.

BRASIL. Decreto n. 7.397, de 22 de dezembro de 2010. 2010. Disponível em: <http://www.planalto.gov.br/ccivil_03/_Ato2007-2010/2010/ Decreto/D7397.htm>. Acesso em: 25 mar. 2019.

CAPELLA, A. C. N. Perspectivas teóricas sobre o processo de formulação de políticas públicas. In: HOCHMAN, G.; ARRETCHE, M.; MARQUES, E. (Orgs.). Políticas públicas no Brasil. Rio de Janeiro: Ed. Fiocruz, 2007. p. 87-122.

CAPELLA, A. C. N. A trajetória das políticas de administração pública na agenda governamental: os governos FHC e Lula. Temas em Administração, v. 2, n. 2, p. 1-14, 2008.

CAPELLA, A. C. N. Um estudo sobre o conceito de empreendedor de políticas públicas: ideias, interesses e mudanças. Cadernos EBAPE. BR, Rio de Janeiro, v. 14, ed. esp., p. 486-505, 2016.

COMITÊ DE REGULAÇÃO E FISCALIZAÇÃO DOS MERCADOS FINANCEIRO, DE CAPITAIS, DE SEGUROS, DE PREVIDÊNCIA E CAPITALIZAÇÃO COREMEC. Deliberação Coremec n. 8, de 19 de junho de 2009. 2009. Disponível em: <http://www.previc.gov.br/regulacao/ normas/deliberacoes/coremec/deliberacao-coremec-no-8-de-19de-junho-de-2009.pdf/view>. Acesso em: 14 jan. 2020.

ESTRATÉGIA NACIONAL DE EDUCAÇÃO FINANCEIRA - ENEF. Quem somos. 2017. Disponível em: <http://www.vidaedinheiro.gov.br/ quemsomos/>. Acesso em: 22 mar. 2019.

ESTRATÉGIA NACIONAL DE EDUCAÇÃO FINANCEIRA - ENEF. Plano Diretor. 2010a. Disponível em: <http://www.vidaedinheiro.gov. br/wp-content/uploads/2017/08/Plano-Diretor-ENEF-EstrategiaNacional-de-Educacao-Financeira.pdf>. Acesso em: 26 mar. 2019.

ESTRATÉGIA NACIONAL DE EDUCAÇÃO FINANCEIRA - ENEF. Anexos ao Plano Diretor. 2010b. Disponível em: <http://www.vidaedinheiro. gov.br/wp-content/uploads/2017/08/Plano-Diretor-ENEF-anexosATUALIZADO_compressed.pdf>. Acesso em: 26 mar. 2019.

GLOBAL PARTNERSHIP FOR FINANCIAL INCLUSION - GPFI. G-20 Principles and Report on Innovative Financial Inclusion. 2010. Disponível em: <https://www.gpfi.org/sites/gpfi/files/documents/ Principles\%20and\%20Report\%20on\%20Innovative\%20Financial\%20 Inclusion_0.pdf>. Acesso em: 18 ago. 2019.

JONES, M. D. et al. A river runs through it: a multiple streams metareview. Policy Studies Journal, v. 44, n. 1, p. 13-36, 2016.

KINGDON, J. W. Agendas, alternatives and public policies. 2. ed. New York: Harper Collins, 1995.

KINGDON, J. W. Como chega a hora de uma ideia? In: SARAVIA, E.; FERRAREZI, E. (Orgs.). Políticas públicas: coletânea. Brasília, DF: Escola Nacional de Administração Pública, 2006a. p. 219-224.

KINGDON, J. W. Juntando as coisas. In: SARAVIA, E.; FERRAREZI, E. (Org.). Políticas públicas: coletânea. Brasília, DF: Escola Nacional de Administração Pública, 2006b. p. 225-245.

MARCH, J. G.; OLSEN, J. P.; COHEN, M. D. A garbage can model of organizational choice. Administrative Science Quartely, v. 17, p. 1-25, 1972.
MARTINS, A. Q. N. A formação da Estratégia Nacional de Educação Financeira do governo brasileiro. Rio de Janeiro: Escola Nacional de Saúde Pública Sergio Arouca, 2013.

MINISTÉRIO DA FAZENDA. Organização para a Cooperação e Desenvolvimento Econômico - OCDE. 2019. Disponível em: <http:// www.fazenda.gov.br/assuntos/atuacao-internacional/cooperacaointernacional/ocde>. Acesso em: 21 mar. 2019.

MUCCIARONI, G. The garbage can model and the study of policy making: a critique. Polity, v. 24, p. 459-482, 1992.

NAGEM F. A.; SILVA, S. P. Institucionalização e execução das políticas públicas de economia solidária no Brasil. Revista de Sociologia e Política, v. 21, n. 46, p. 159-175, 2013.

NERI, M. C., CARVALHAES, L. Miséria e a nova classe média na década da igualdade. Rio de Janeiro: FGV/IBRE, 2008.

ORGANISATION FOR ECONOMIC CO-OPERATION AND DEVELOPMENT - OECD. OECD's Financial Education Project. 2004. Disponível em: <https://www.oecd.org/finance/financial-education/33865427.pdf>. Acesso em: 10 mar. 2019.

ORGANISATION FOR ECONOMIC CO-OPERATION AND DEVELOPMENT - OECD. Recommendation on principles and good practices for financial education and awareness. 2005a. Disponível em: $<\mathrm{http}: / /$ www.oecd.org/daf/fin/financial-education/35108560.pdf>. Acesso em: 26 mar. 2019.

ORGANISATION FOR ECONOMIC CO-OPERATION AND DEVELOPMENT - OECD. Improving financial literacy: analysis of issues and policies. 2005b. Disponível em: <https://read.oecd-ilibrary.org/finance-andinvestment/improving-financial-literacy_9789264012578-en>. Acesso em: 26 mar. 2019.

ORGANISATION FOR ECONOMIC CO-OPERATION AND DEVELOPMENT - OECD; GROUP OF TWENTY - G20. Advancing national strategies for financial education. 2013. Disponível em: <https://www.oecd. org/finance/financial-education/G20_OECD_NSFinancialEducation. pdf>. Acesso em: 26 mar. 2019.

ORGANISATION FOR ECONOMIC CO-OPERATION AND DEVELOPMENT - OECD. Highlights on national strategies for financial education policy handbook. 2015. Disponível em: <https://www.oecd.org/ $\mathrm{daf} /$ fin/financial-education/National-Strategies-Financial-EducationPolicy-Handbook-Highlights.pdf>. Acesso em: 26 mar. 2019.

PEREIRA, M. C. G.; TEIXEIRA, M. A. C. A inclusão de catadores em programas de coleta seletiva: da agenda local à nacional. Cadernos EBAPE.BR, Rio de Janeiro, v. 9, n. 3, p. 895-913, 2011.

PINTO, I. C. M. Construção da agenda governamental: atores, arenas e processo decisório na saúde. Organizações \& Sociedade, v. 15, n. 44, p. 13-23, 2008.

SABATIER, P. A. Fostering the development of policy theory. In: SABATIER, P. A. (Ed.). Theories of the policy process. Cambridge: Westview Press, 2007. p. 321-336.

SOUZA, C. Políticas públicas: uma revisão da literatura. Sociologias, v. 8, n. 16, p. 29-35, 2006. 
VIANA, A. L. Abordagens metodológicas em políticas públicas. Revista de Administração Pública, Rio de Janeiro, v. 30, n. 2, p. 5-43, 1996.
ZAHARIADIS, N. The multiple streams framework: structure, limitations, prospects. In: SABATIER, P. A. (Ed.). Theories of the policy process. Cambridge: Westview Press, 2007. p. 65-92. 